farms and after the removal of wings and limbs are cooked with soy sauce and sugar, and served. The merits of the practice are twofold: first, the use of a good source of animal protein, particularly notable in a country which until a century ago detested killing land mammals; second, as Treherne pointed out, removal of an agricultural pest.

Processed rice hoppers (mainly from Nagano prefecture) called tsukudani are sold in packets in supermarkets and are mainly eaten as a snack with alcoholic beverages. In addition to rice hoppers, wasp maggots (hachinoko) are also eaten in Japan. The National Food Composition Tables (Resources Council, Standard Tables of Food Composition in Japan, 4th edn; Science and Technology Agency, Tokyo, 1982) provide the nutritional composition of tsukudani from Oxya yezoensis Shiraki and canned maggot of the wasp Vespa japonica Saussure. Their protein compositions are 22.5 and 15.7 grams per 100 grams of edible portion, respectively.

Sachi SRI Kantha

Laboratory of Marine Biochemistry,

Faculty of Agriculture,

University of Tokyo,

Bunkyo-ku, Tokyo 113, Japan

\section{Latex gloves off in virus porosity dispute}

SIR-Two of the authors of the recent letter' about latex gloves and viruses, are at Advanced Biotechnologies Inc., which may explain their ignoring a century of microbiology. Pasteur showed that broth remains sterile in a flask stoppered with an open glass tube if the tube has two to three bends. Particles hate labyrinths and get stuck in the first or second corner. Sterilization by filtration through candles or membranes was always based on the principle that pores may be much larger than the microbe to be stopped.

Arnold et al. show a nice electronmicrograph with channels and pores in the latex glove but provide no evidence that viruses pass through them. Contrary results $^{2}$ are unjustly rejected. The use of several gloves is certainly interesting for the glove industry but may reduce the handling skill of operators.

Institut de Cancerologie et

JOSEPH HUPPERT George Mathe

Immunogénétique,

94800 Villejuif, France

SIR-Arnold et al. ' report that latex gloves have pits on both interior and exterior surfaces as judged by scanning electron microscopy. They compare their findings to ours ${ }^{2}$ and conclude that double gloving, possibly supplemented by surfactant virucide, would be prudent for those handling material infected by HIV or hepatitis B virus.

Our study used reputable gloves avail- able to laboratories and hospitals, and a full description and source of all the gloves was given. Although we did not look for cavities by electron microscopy, we reported that even in the event of a breach of the latex rubber the virus in contact with latex seems to be inactivated.

None of the gloves tested by Arnold et $a l$. are listed in their letter and one of the authors (C.H. Fox) has led us to believe that the gloves used were known not to be of high quality relative to medical applications. It is very important that the type of glove, the type of latex and the processes used to make the latex are taken into consideration, especially before reporting what could be construed as alarming results.

A.G. Dalgleish Mirek Malkovsky

\section{Clinical Research Centre,}

Harrow, Middlesex HA1 3UJ, UK

SIR-We wish to correct the impression given by Arnold et al. ' that latex gloves contain micronsized fissures or channels impairing their integrity.

We have been examining latex gloves, condoms and other latex products for many years, using transmission and scanning electron microscopy as well as energy-dispersive X-ray analysis. The surfaces of latex films may sometimes exhibit pits or protuberances, and crosssections of films may reveal residual particle interfaces, but the presence of "ducts" or "channels" has never been observed even at moderately high magnifications.

In our view the "5-micron tortuous channels" reported by Arnold et al. are probably artefacts of sample preparation. It is usual, in preparation for electron microscopy, to apply an electrically conductive coating to polymers. The coating may be of carbon, gold or gold-palladium alloy, or combinations of these.

Unless precautions are taken during the coating process, and subsequent examination of specimens, it is possible to produce artefacts which strongly resemble the "channels" shown in the published micrograph.

We conclude that Arnold et al. were misled by cracking of the coating applied during sample preparation. Their recommendation that two pairs of gloves are required to ensure adequate protection is therefore unnecessary.

T. D. Pendle A. J. CobBold Tun Abdul Razak Laboratory,

\section{Brickendonbury,}

\section{Hertford SG13 $8 N L, U K$}

Arnold. S.G., Whitman. J.E. Jr, Fox. C.H. \& CottlerFox. M.H. Nature 335, 19 (1988).

2. Datgleish. A.G. \& Malkovsky. M. Brit. J. Surg. 76. 171-172(1988).

- Two of the authors of the letter "Latex gloves not enough to exclude viruses" have since moved. The present address for S.G. Arnold and J.E. Whitman $\mathrm{J}_{\mathrm{r}}$ is: Advanced Biotechnologics Inc. Rivers Park II 9108 Guilford Road. Columbia. Maryland 21046. USA

\section{Magnetic reversal rate and global sea level trends}

SIR-Morris and Muller ${ }^{1}$ recently commented on Gaffin's ${ }^{2}$ finding of a negative correlation between the long-term trend in global sea level over the past $150 \mathrm{Myr}$ the so-called first-order sea-level curve of Vail et $a l^{3}{ }^{3}$ - and the frequency of geomagnetic reversals. In order to support their hypothesis that reversals are caused by sudden climate coolings and drops in sea level $^{4}$, however, they persist in the erroneous conclusion of their earlier paper, that the period of generally high sea level during the Cretaceous, from about 80 to 120 Myr BP, was also a time of a reduced number of shorter term (second-order) sea-level fluctuations (see figure). This conclusion was based on the use of the

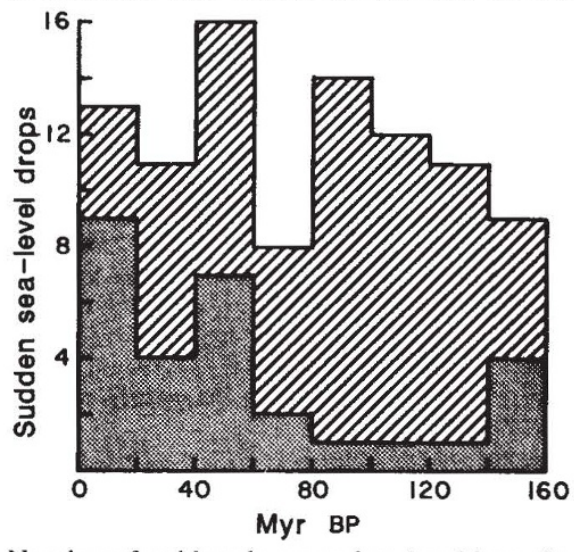

Number of sudden changes of sea level from the 1977 (stippled) and 1987 (stripes) data of Vail and colleagues.

data of Vail et al. at which deliberately excluded a detailed curve of Cretaceous sea-level oscillations for proprietary reasons.

When one uses the new sea-level curve of Haq et al. ${ }^{5}$, which includes the previously unreleased Cretaceous data, the number of rapid changes of sea level in the Cretaceous is similar to that in the post-Cretaceous interval (see figure). The lack of magnetic reversals during the Cretaceous 'quiet' interval, therefore, is not matched by any lack of short-term changes in sea level during that time. Thus, the data seem not to support the Morris and Muller hypothesis. One way to resurrect the hypo thesis, however, would be to suggest that during the quiet interval, the core of the Earth was less susceptible to the disturbances caused by rapid sea-level changes resulting from extraterrestrial impacts.

Department of Applied Science,

M. R. RAMPINO

New York University,

New York, New York 10003, USA

1. Muller, R.A. \& Morris D.E. Nature 332. 211 (1988).

2. Gaffin. S. Nature 329, 816-819 (1987).

Vail, P.R. et al. Am. Ass. Petrol. Geol. Mem. 26.83 (1977)

Muller. R.A. \& Morris, D.E. Geophys. Res. Lett. 13 $1177-1180(1987)$

. Haq. B.U..et al. Science 235, 1156-1167 (1987).

6. Rampino, M.R. Phys. Today 41, 121-122 (1988). 